\title{
Convergence of perturbed composite implicit iteration process for a finite family of asymptotically nonexpansive mappings
}

\section{Xuewu Wang*}

"Correspondence:

wangxuewuxx@163.com School of Mathematics and

Information Science, Shandong Institute of Business and

Technology, Yantai, Shandong

264005, China

\begin{abstract}
In this paper, we introduce a perturbed composite implicit iterative process with errors for a finite family of asymptotically nonexpansive mappings. Under Opial's condition, semicompact and $\liminf _{n \rightarrow \infty} d\left(x_{n}, F(T)\right)=0$ conditions, respectively, we prove that this iterative scheme converges weakly or strongly to a common fixed point of a finite family of asymptotically nonexpansive mappings in uniformly convex Banach spaces. The results presented in this paper generalize and improve the corresponding results of Sun (J. Math. Anal. Appl. 286:351-358, 2003), Chang (J. Math. Anal. Appl. 313:273-283, 2006), Gu (J. Math. Anal. Appl. 329:766-776, 2007), Thakur (Appl. Math. Comput. 190:965-973, 2007), Rafiq (Rostock. Math. Kolloqu. 62:21-39, 2007) and some others.
\end{abstract}

MSC: $47 \mathrm{H} 9 ; 47 \mathrm{H} 10$

Keywords: asymptotically nonexpansive mapping; uniformly convex Banach space; perturbation; composite implicit iterative process; weak and strong convergence; common fixed point

\section{Introduction}

Let $E$ be a real Banach space, $K$ be a nonempty convex subset of $E$. Let $\left\{T_{1}, T_{2}, \ldots, T_{N}\right\}$ be a finite family of mappings from $K$ into itself, and $F\left(T_{i}\right)$ be the set of fixed points of $T_{i}$ $(i \in I=\{1,2, \ldots, N\}) . F(T)$ denotes the set of common fixed points of $\left\{T_{1}, T_{2}, \ldots, T_{N}\right\}$.

Recently, $\mathrm{Xu}$ and Ori [1] have introduced an implicit iteration process for a finite family of nonexpansive mappings as follows:

$$
x_{n}=\alpha_{n} x_{n-1}+\left(1-\alpha_{n}\right) T_{n} x_{n}, \quad \forall n \geq 1,
$$

where $T_{n}=T_{n(\bmod N)}$ (here the $\bmod N$ function takes values in $\left.I\right),\left\{\alpha_{n}\right\}$ be a real sequence in $[0,1], x_{0}$ be an initial point in $K$.

Sun [2] have extended this iterative process defined by $\mathrm{Xu}$ and Ori to a new iterative process for a finite family of asymptotically nonexpansive mappings, which is defined as follows:

$$
x_{n}=\alpha_{n} x_{n-1}+\left(1-\alpha_{n}\right) T_{i}^{k} x_{n}, \quad n \geq 1,
$$

where $n=(k-1) N+i, i \in I$.

0 2013 Wang: licensee Springer. This is an Open Access article distributed under the terms of the Creative Commons Attribution License (http://creativecommons.org/licenses/by/2.0), which permits unrestricted use, distribution, and reproduction in any medium, provided the original work is properly cited. 
Chang [3] have discussed the convergence of the implicit iteration process with errors for a finite family of asymptotically nonexpansive mappings as follows:

$$
x_{n}=\alpha_{n} x_{n-1}+\left(1-\alpha_{n}\right) T_{i(n)}^{k(n)} x_{n}+u_{n}, \quad n \geq 1,
$$

where $n=(k(n)-1) N+i(n), i(n) \in I$, and $k(n) \geq 1$ with $k(n) \rightarrow \infty$ as $n \rightarrow \infty$. Under the hypotheses $\sum_{n=1}^{\infty}\left\|u_{n}\right\|<\infty$ and some appropriate conditions, they proved some results of weak and strong convergence for $\left\{x_{n}\right\}$ defined by (3). However, the condition $\sum_{n=1}^{\infty}\left\|u_{n}\right\|<$ $\infty$ is not too reasonable, because this implies that $\left\{u_{n}\right\}$ are very small for $n$ sufficiently big.

$\mathrm{Gu}[4]$ has extended the above implicit iteration processes. A composite implicit iteration process with random errors was introduced as follows:

$$
\left\{\begin{array}{l}
x_{n}=\left(1-\alpha_{n}-\gamma_{n}\right) x_{n-1}+\alpha_{n} T_{n} y_{n}+\gamma_{n} u_{n}, \quad n \geq 1 \\
y_{n}=\left(1-\beta_{n}-\delta_{n}\right) x_{n}+\beta_{n} T_{n} x_{n}+\delta_{n} v_{n}, \quad n \geq 1
\end{array}\right.
$$

where $\left\{\alpha_{n}\right\},\left\{\beta_{n}\right\},\left\{\gamma_{n}\right\},\left\{\delta_{n}\right\}$ are four real sequences in $[0,1]$ satisfying $\alpha_{n}+\gamma_{n} \leq 1$ and $\beta_{n}+$ $\delta_{n} \leq 1$ for all $n \geq 1,\left\{u_{n}\right\},\left\{v_{n}\right\}$ are two sequences in $K$ and $x_{0}$ is an initial point. Some theorems were established on the strong convergence of the composite implicit iteration process defined by (4) for a finite family of mappings in real Banach spaces.

Thakur [5] has improved the composite implicit iteration process defined by (4) as follows:

$$
\left\{\begin{array}{l}
x_{n}=\left(1-\alpha_{n}\right) x_{n-1}+\alpha_{n} T_{i(n)}^{k(n)} y_{n}, \quad n \geq 1 \\
y_{n}=\left(1-\beta_{n}\right) x_{n}+\beta_{n} T_{i(n)}^{k(n)} x_{n}, \quad n \geq 1
\end{array}\right.
$$

Some theorems were proved on the weak and strong convergence of the composite implicit iteration process defined by (5) for a finite family of mappings in real uniformly convex Banach spaces.

Rafiq [6] have improved the implicit iterative process. The Mann type implicit iteration process was introduced in Hilbert spaces as follows:

$$
x_{n}=\alpha_{n} x_{n-1}+\left(1-\alpha_{n}\right) T v_{n}, \quad n \geq 1,
$$

where $v_{n}$ is a perturbation of $x_{n}$, and satisfy $\sum_{n \geq 1}\left\|x_{n}-v_{n}\right\|<\infty$. Moreover, Ciric [7] also did some work in this respect.

Inspired and motivated by the above works, in this paper we will extend and improve the above iterative process to a perturbed composite implicit iterative process for a finite family of asymptotically nonexpansive mappings as follows:

$$
\begin{cases}x_{n}=\left(1-\alpha_{n}-\gamma_{n}\right) x_{n-1}+\alpha_{n} T_{i(n)}^{k(n)} y_{n}+\gamma_{n} u_{n}, & n \geq 1 ; \\ y_{n}=\left(1-\beta_{n}-\delta_{n}\right) x_{n-1}+\beta_{n} T_{i(n)}^{k(n)} \tilde{x}_{n}+\delta_{n} v_{n}, & n \geq 1,\end{cases}
$$

where $n=(k(n)-1) N+i(n), i(n) \in I, T_{n}=T_{n(\bmod N)},\left\{\alpha_{n}\right\},\left\{\beta_{n}\right\},\left\{\gamma_{n}\right\},\left\{\delta_{n}\right\}$ are four real sequences in [0,1] satisfying $\alpha_{n}+\gamma_{n} \leq 1$ and $\beta_{n}+\delta_{n} \leq 1$ for all $n \geq 1,\left\{u_{n}\right\},\left\{v_{n}\right\}$ are two sequences in $K$ and $x_{0}$ is an initial point. $\left\{\tilde{x}_{n}\right\}$ be a sequence in $K$ satisfying $\sum_{n \geq 1}\left\|x_{n}-\tilde{x}_{n}\right\|<$ 
$\infty$, which implies that $\left\|x_{n}-\tilde{x}_{n}\right\| \rightarrow 0(n \rightarrow \infty)$. Therefore, $\tilde{x}_{n}$ is known as the perturbation of $x_{n}$, and $\left\{\tilde{x}_{n}\right\}$ is known as the perturbed sequence of $\left\{x_{n}\right\}$. This sequence $\left\{x_{n}\right\}$ defined by (7) is said to be the perturbed composite implicit iterative sequence with random errors.

Especially, (I) in the iterative process defined by (7), when $\beta_{n}=0, \delta_{n}=0$ for all $n \geq 1$, we have

$$
x_{n}=\left(1-\alpha_{n}-\gamma_{n}\right) x_{n-1}+\alpha_{n} T_{i(n)}^{k(n)} x_{n-1}+\gamma_{n} u_{n}, \quad n \geq 1 .
$$

At this time, the perturbed composite implicit iterative sequence generated by (7) becomes a Mann-type iterative sequence with random errors.

(II) In the iterative process defined by (7), when $\beta_{n}=1, \delta_{n}=0$ for all $n \geq 1$, we have

$$
x_{n}=\left(1-\alpha_{n}-\gamma_{n}\right) x_{n-1}+\alpha_{n} T_{i(n)}^{2 k(n)} \tilde{x}_{n}+\gamma_{n} u_{n}, \quad n \geq 1 .
$$

At this time, the perturbed composite implicit iterative sequence generated by (7) becomes a perturbed implicit iterative sequence with random errors.

(III) In the iterative process defined by (7), when $x_{n-1}=\tilde{x}_{n}$ for all $n \geq 1$, we have

$$
\left\{\begin{array}{l}
x_{n}=\left(1-\alpha_{n}-\gamma_{n}\right) x_{n-1}+\alpha_{n} T_{i(n)}^{k(n)} y_{n}+\gamma_{n} u_{n}, \quad n \geq 1 ; \\
y_{n}=\left(1-\beta_{n}-\delta_{n}\right) x_{n-1}+\beta_{n} T_{i(n)}^{k(n)} x_{n-1}+\delta_{n} v_{n}, \quad n \geq 1 .
\end{array}\right.
$$

At this time, the perturbed composite implicit iterative sequence generated by (7) becomes an Ishikawa-type iterative sequence with random errors for a finite family of asymptotically nonexpansive mappings $\left\{T_{i}, i \in I\right\}$.

From the above iterative processes defined by (1)-(6) and (8)-(10), we know that the iterative process (7) improves and extends some iterative process introduced by the recent literature. Moreover, we point out that the iterative process, defined by (7), in which it is not necessary to compute the value of the given operator at $x_{n}$, but compute an approximate point of $x_{n}$, are particularly useful in the numerical analysis. Therefore, the iterative sequence generated by (7) is better than some implicit iterative sequences at the existent aspect.

The main purpose of this paper is to study the convergence of the perturbed composite implicit iterative sequence $\left\{x_{n}\right\}$ defined by (7) for a finite family of asymptotically nonexpansive mappings under Opial's condition, semicompact and $\liminf _{n \rightarrow \infty} d\left(x_{n}, F(T)\right)=0$ conditions, respectively. The results presented in this paper generalized and improve the corresponding results of Sun [2], Chang [3], Gu [4], Thakur [5], Rafiq [6], and some others $[1,7-15]$.

\section{Preliminaries}

For the sake of convenience, we first recall some definitions and conclusions.

Definition 2.1 Let $K$ be a closed subset of the real Banach space $E$ and $T: K \rightarrow K$ be a mapping.

1. $\quad T$ is said to be semicompact, if for any bounded sequence $\left\{x_{n}\right\}$ in $K$ such that $\left\|T x_{n}-x_{n}\right\| \rightarrow 0(n \rightarrow \infty)$, then there exists a subsequence $\left\{x_{n_{i}}\right\}$ of $\left\{x_{n}\right\}$ such that $x_{n_{i}} \rightarrow x^{*} \in E$; 
2. $T$ is said to be demiclosed at the origin, if for each sequence $\left\{x_{n}\right\}$ in $K$, the conditions $x_{n} \rightarrow x_{0}$ weakly and $T x_{n} \rightarrow 0$ strongly imply $T x_{0}=0$;

3. $T$ is said to be asymptotically nonexpansive, if there exists a sequence $h_{n} \in[1,+\infty)$ with $\lim _{n \rightarrow \infty} h_{n}=1$ such that

$$
\left\|T^{n} x-T^{n} y\right\| \leq h_{n}\|x-y\|, \quad \forall x, y \in K, n \geq 1
$$

4. Let $T$ is said to be uniformly $L$-Lipschitizian if there exists a constant $L>0$ such that

$$
\left\|T^{n} x-T^{n} y\right\| \leq L\|x-y\|, \quad \forall x, y \in E, n \geq 1
$$

Definition 2.2 [16] A Banach space $X$ is said to satisfy Opial's condition if $x_{n} \rightarrow x$ weakly as $n \rightarrow \infty$ and $x \neq y$ imply that $\limsup _{n \rightarrow \infty}\left\|x_{n}-x\right\|<\limsup _{n \rightarrow \infty}\left\|x_{n}-y\right\|$.

Lemma 2.1 Let $K$ be a nonempty subset of $E, T_{1}, T_{2}, \ldots, T_{N}: K \rightarrow K$ be $N$ asymptotically nonexpansive mappings. Then

(i) there exists a sequence $\left\{h_{n}\right\} \subset[1,+\infty)$ with $\lim _{n \rightarrow \infty} h_{n}=1$ such that

$$
\left\|T_{i}^{n} x-T_{i}^{n} y\right\| \leq h_{n}\|x-y\|, \quad \forall x, y \in K, i \in I, n \geq 1
$$

(ii) $\left\{T_{1}, T_{2}, \ldots, T_{N}\right\}$ is uniformly Lipschitzian, i.e., there exists a constant $L$ such that

$$
\left\|T_{i}^{n} x-T_{i}^{n} y\right\| \leq L\|x-y\|, \quad \forall x, y \in K, i \in I, n \geq 1 .
$$

Proof Since $T_{1}, T_{2}, \ldots, T_{N}: K \rightarrow K$ are $N$ asymptotically nonexpansive mappings, then for every $i \in I$ and $n \in N$, there exists $h_{n}^{(i)} \in[1,+\infty)$ with $\lim _{n \rightarrow \infty} h_{n}^{(i)}=1$ such that

$$
\left\|T_{i}^{n} x-T_{i}^{n} y\right\| \leq h_{n}^{(i)}\|x-y\|, \quad \forall x, y \in E .
$$

Taking $h_{n}=\max \left\{h_{n}^{(1)}, h_{n}^{(2)}, \ldots, h_{n}^{(N)}\right\}$, then $h_{n} \subset[1,+\infty), \lim _{n \rightarrow \infty} h_{n}=1$ and (12) holds.

An asymptotically nonexpansive mapping must is a uniformly Lipschitzian mapping. Hence, for every $i \in I$ and $n \in N$, there exists $L_{i}$ such that

$$
\left\|T_{i}^{n} x-T_{i}^{n} y\right\| \leq L_{i}\|x-y\|, \quad \forall x, y \in E .
$$

Taking $L=\max \left\{L_{1}, L_{2}, \ldots, L_{N}\right\}$, it is obvious that (13) holds.

Lemma 2.2 [17] Let E be a uniformly convex Banach space, $K$ be a nonempty, closed and convex subset of $E$ and $T: K \rightarrow K$ be an asymptotically nonexpansive mapping. Then $I-T$ is demi-closed at zero, i.e., for each sequence $\left\{x_{n}\right\}$ in $K$, if $\left\{x_{n}\right\}$ convergence weakly to $q \in E$ and $\left\{(I-T) x_{n}\right\}$ converges strongly to 0 , then $(I-T) q=0$.

Lemma 2.3 [18] Let E be a Banach space satisfying Opial's condition, $\left\{x_{n}\right\}$ be a sequence in E. Let $u, v \in E$ be such that $\lim _{n \rightarrow \infty}\left\|x_{n}-u\right\|$ and $\lim _{n \rightarrow \infty}\left\|x_{n}-v\right\|$ exist. If $\left\{x_{n_{k}}\right\}$ and $\left\{x_{n_{l}}\right\}$ are two subsequences of $\left\{x_{n}\right\}$ which converge weakly to $u$ and $v$, respectively, then $u=v$. 
Lemma 2.4 [19] Let E be a uniformly convex Banach space, $b$, c be two constants with $0<$ $b<c<1$. Suppose that $\left\{t_{n}\right\}$ is a sequence in $[b, c]$ and $\left\{x_{n}\right\},\left\{y_{n}\right\}$ are two sequences in $E$. Then the conditions $\lim _{n \rightarrow \infty}\left\|t_{n} x_{n}+\left(1-t_{n}\right) y_{n}\right\|=d$, limsup $\sup _{n \rightarrow \infty}\left\|x_{n}\right\| \leq d, \lim \sup _{n \rightarrow \infty}\left\|y_{n}\right\| \leq d$ imply that $\lim _{n \rightarrow \infty}\left\|x_{n}-y_{n}\right\|=0$, where $d$ is a nonnegative constant.

Lemma $2.5[20]$ Let $\left\{a_{n}\right\},\left\{b_{n}\right\},\left\{\delta_{n}\right\}$ are three sequences of nonnegative real numbers, if there exists $n_{0}$ such that

$$
a_{n+1} \leq\left(1+\delta_{n}\right) a_{n}+b_{n}, \quad \forall n>n_{0},
$$

where $\sum_{n=1}^{\infty} \delta_{n}<\infty$ and $\sum_{n=1}^{\infty} b_{n}<\infty$. Then

(i) $\lim _{n \rightarrow \infty} a_{n}$ exists;

(ii) $\lim _{n \rightarrow \infty} a_{n}=0$ whenever $\liminf _{n \rightarrow \infty} a_{n}=0$.

Lemma 2.6 Let $E$ be a real Banach space and $K$ be a nonempty closed convex subset of $E$. Let $T_{1}, T_{2}, \ldots, T_{N}: K \rightarrow K$ be $N$ asymptotically nonexpansive mappings with $F(T)=\bigcap_{i=1}^{N} F\left(T_{i}\right) \neq \varnothing$. Let $\left\{u_{n}\right\}$ and $\left\{v_{n}\right\}$ are two bounded sequences in $K$. If $\left\{\alpha_{n}\right\},\left\{\beta_{n}\right\}$, $\left\{\gamma_{n}\right\},\left\{\delta_{n}\right\}$ be four real sequences in $[0,1]$ satisfying the following conditions:

(i) $\alpha_{n}+\gamma_{n} \leq 1$ and $\beta_{n}+\delta_{n} \leq 1$ for all $n \geq 1$;

(ii) $\lim \sup _{n \rightarrow \infty} \alpha_{n}=\alpha<1$ or $\lim \sup _{n \rightarrow \infty} \beta_{n}=\beta<1$;

(iii) $\sum_{n=1}^{\infty} \gamma_{n}<\infty, \sum_{n=1}^{\infty} \delta_{n}<\infty, \sum_{n=1}^{\infty}\left(h_{n}-1\right)<\infty$;

(iv) $\sum_{n=1}^{\infty}\left\|\tilde{x}_{n}-x_{n}\right\|<\infty$.

Let $\left\{x_{n}\right\}$ be the perturbed composite implicit iterative sequence defined by (7), then $\lim _{n \rightarrow \infty}\left\|x_{n}-p\right\|$ exists for all $p \in F(T)$.

Proof Take $p \in F(T)$, it follows from (7) and Lemma 2.1 that

$$
\begin{aligned}
\left\|x_{n}-p\right\| & \leq\left\|\left(1-\alpha_{n}-\gamma_{n}\right) x_{n-1}+\alpha_{n} T_{i(n)}^{k(n)} y_{n}+\gamma_{n} u_{n}-p\right\| \\
& \leq\left(1-\alpha_{n}-\gamma_{n}\right)\left\|x_{n-1}-p\right\|+\alpha_{n} h_{n}\left\|y_{n}-p\right\|+\gamma_{n}\left\|u_{n}-p\right\|
\end{aligned}
$$

and

$$
\begin{aligned}
\left\|y_{n}-p\right\| & \leq\left\|\left(1-\beta_{n}-\delta_{n}\right) x_{n-1}+\beta_{n} T_{i(n)}^{k(n)} \tilde{x}_{n}+\delta_{n} v_{n}-p\right\| \\
& \leq\left(1-\beta_{n}-\delta_{n}\right)\left\|x_{n-1}-p\right\|+\beta_{n} h_{n}\left\|\tilde{x}_{n}-p\right\|+\delta_{n}\left\|v_{n}-p\right\| \\
& \leq\left(1-\beta_{n}-\delta_{n}\right)\left\|x_{n-1}-p\right\|+\beta_{n} h_{n}\left\|\tilde{x}_{n}-x_{n}\right\|+\beta_{n} h_{n}\left\|x_{n}-p\right\|+\delta_{n}\left\|v_{n}-p\right\| .
\end{aligned}
$$

Substituting (15) into (14) and simplifying, we obtain

$$
\begin{aligned}
\left(1-\alpha_{n} \beta_{n} h_{n}^{2}\right)\left\|x_{n}-p\right\| \leq & {\left[1-\alpha_{n}-\gamma_{n}+\alpha_{n} h_{n}\left(1-\beta_{n}-\delta_{n}\right)\right]\left\|x_{n-1}-p\right\| } \\
& +\alpha_{n} \beta_{n} h_{n}^{2}\left\|\tilde{x}_{n}-x_{n}\right\|+\alpha_{n} \delta_{n} h_{n}\left\|v_{n}-p\right\|+\gamma_{n}\left\|u_{n}-p\right\| .
\end{aligned}
$$

We notice the hypotheses on $\left\{\alpha_{n}\right\},\left\{\beta_{n}\right\}$ and $\left\{h_{n}\right\}$, by $\lim \sup _{n \rightarrow \infty} \alpha_{n}=\alpha<1$, there exists $n_{0} \in N$ such that

$$
1-\alpha_{n} \beta_{n} h_{n}^{2} \geq 1-\alpha_{n} h_{n}^{2} \geq \frac{1}{2}(1-\alpha)>0, \quad n \geq n_{0} .
$$


It follows from (16) that for $n \geq n_{0}$

$$
\begin{aligned}
\left\|x_{n}-p\right\| \leq & \frac{1-\alpha_{n}-\gamma_{n}+\alpha_{n} h_{n}\left(1-\beta_{n}-\delta_{n}\right)}{1-\alpha_{n} \beta_{n} h_{n}^{2}}\left\|x_{n-1}-p\right\| \\
& +\frac{1}{1-\alpha_{n} \beta_{n} h_{n}^{2}}\left(\alpha_{n} \beta_{n} h_{n}^{2}\left\|\tilde{x}_{n}-x_{n}\right\|+\alpha_{n} \delta_{n} h_{n}\left\|v_{n}-p\right\|+\gamma_{n}\left\|u_{n}-p\right\|\right) \\
\leq & {\left[1+\frac{\alpha_{n} \beta_{n} h_{n}^{2}-\alpha_{n}+\alpha_{n} h_{n}\left(1-\beta_{n}\right)}{1-\alpha_{n} \beta_{n} h_{n}^{2}}\right]\left\|x_{n-1}-p\right\| } \\
& +\frac{2}{1-\alpha}\left(\alpha_{n} \beta_{n} h_{n}^{2}\left\|\tilde{x}_{n}-x_{n}\right\|+\alpha_{n} \delta_{n} h_{n}\left\|v_{n}-p\right\|+\gamma_{n}\left\|u_{n}-p\right\|\right) \\
\leq & \left\{1+\frac{2}{1-\alpha}\left[\alpha_{n} \beta_{n} h_{n}\left(h_{n}-1\right)+\alpha_{n}\left(h_{n}-1\right)\right]\right\}\left\|x_{n-1}-p\right\| \\
& +\frac{2}{1-\alpha}\left(\alpha_{n} \beta_{n} h_{n}^{2}\left\|\tilde{x}_{n}-x_{n}\right\|+\alpha_{n} \delta_{n} h_{n}\left\|v_{n}-p\right\|+\gamma_{n}\left\|u_{n}-p\right\|\right) .
\end{aligned}
$$

Hence, we have

$$
\left\|x_{n}-p\right\| \leq\left(1+\theta_{n}\right)\left\|x_{n-1}-p\right\|+\eta_{n}, \quad n \geq n_{0}
$$

where

$$
\theta_{n}=\frac{2}{1-\alpha}\left[\alpha_{n} \beta_{n} h_{n}\left(h_{n}-1\right)+\alpha_{n}\left(h_{n}-1\right)\right], \quad n \geq n_{0}
$$

and

$$
\eta_{n}=\frac{2}{1-\alpha}\left(\alpha_{n} \beta_{n} h_{n}^{2}\left\|\tilde{x}_{n}-x_{n}\right\|+\alpha_{n} \delta_{n} h_{n}\left\|v_{n}-p\right\|+\gamma_{n}\left\|u_{n}-p\right\|\right), \quad n \geq n_{0}
$$

From condition (iii), it is obvious that $\sum_{n=1}^{\infty} \theta_{n}<\infty$. In addition, since $\left\{\left\|u_{n}\right\|\right\},\left\{\left\|v_{n}\right\|\right\}$ are all bounded, we deduce that $\sum_{n=1}^{\infty} \eta_{n}<\infty$ form (iii)-(iv). By virtue of (17) and Lemma 2.5, we obtain that $\lim _{n \rightarrow \infty}\left\|x_{n}-p\right\|$ exists. This completes the proof of Lemma 2.6.

\section{Main results and proofs}

Theorem 3.1 Let E be a real Banach space and $K$ be a nonempty, closed and convex subset of E. Let $T_{1}, T_{2}, \ldots, T_{N}: K \rightarrow K$ be $N$ asymptotically nonexpansive mappings with $F(T)=$ $\bigcap_{i=1}^{N} F\left(T_{i}\right) \neq \varnothing$. Let $\left\{u_{n}\right\}$ and $\left\{v_{n}\right\}$ are two bounded sequences in $K$. If $\left\{\alpha_{n}\right\},\left\{\beta_{n}\right\},\left\{\gamma_{n}\right\},\left\{\delta_{n}\right\}$ be four real sequences in $[0,1]$ satisfying the following conditions:

(i) $\alpha_{n}+\gamma_{n} \leq 1$ and $\beta_{n}+\delta_{n} \leq 1$ for all $n \geq 1$;

(ii) $\limsup _{n \rightarrow \infty} \alpha_{n}<1$ or $\limsup _{n \rightarrow \infty} \beta_{n}<1$;

(iii) $\sum_{n=1}^{\infty} \gamma_{n}<\infty, \sum_{n=1}^{\infty} \delta_{n}<\infty, \sum_{n=1}^{\infty}\left(h_{n}-1\right)<\infty$;

(iv) $\sum_{n=1}^{\infty}\left\|\tilde{x}_{n}-x_{n}\right\|<\infty$.

Then the perturbed composite implicit iterative sequence $\left\{x_{n}\right\}$ defined by (7) converges strongly to a common fixed point of $\left\{T_{1}, T_{2}, \ldots, T_{N}\right\}$ if and only if $\liminf _{n \rightarrow \infty} d\left(x_{n}, F(T)\right)=0$.

Proof The necessity of Theorem 3.1 is obvious. Now we prove the sufficiency of Theorem 3.1. 
For arbitrary $p \in F(T)$, it follows from (17) in Lemma 2.6 that

$$
\left\|x_{n}-p\right\| \leq\left(1+\theta_{n}\right)\left\|x_{n-1}-p\right\|+\eta_{n}, \quad \forall n \geq n_{0},
$$

where $\sum_{n=1}^{\infty} \theta_{n}<\infty$ and $\sum_{n=1}^{\infty} \eta_{n}<\infty$. Hence, we have

$$
d\left(x_{n}, F(T)\right) \leq\left(1+\theta_{n}\right) d\left(x_{n-1}, F(T)\right)+\eta_{n}, \quad \forall n \geq n_{0} .
$$

It follows from (18) and Lemma 2.5 that limit $\lim _{n \rightarrow \infty} d\left(x_{n}, F(T)\right)$ exists. By the assumption, we have $\lim _{n \rightarrow \infty} d\left(x_{n}, F(T)\right)=0$. Consequently, for any given $\varepsilon>0$, there exists a positive integer $N_{1}\left(N_{1}>n_{0}\right)$ such that

$$
d\left(x_{n}, F(T)\right)<\frac{\varepsilon}{8}, \quad \sum_{k=n}^{\infty} \eta_{k}<\frac{\varepsilon}{8}, \quad \sum_{k=n}^{\infty} \theta_{k}<1, \quad \forall n \geq N_{1} \text {, }
$$

and there exists $p_{1} \in F(T)$ such that $\left\|x_{n}-p_{1}\right\|<\varepsilon / 8, \forall n \geq N_{1}$. By (18) and the inequality $1+x \leq \mathrm{e}^{x}(x \geq 0)$, for any $n \geq N_{1}$ and all $m \geq 1$, we have

$$
\begin{aligned}
\left\|x_{n+m}-x_{n}\right\| \leq & \exp \left\{\theta_{n+m-1}\right\}\left\|x_{n+m-1}-p_{1}\right\|+\eta_{n+m-1}+\left\|x_{n}-p_{1}\right\| \\
\leq & \exp \left\{\theta_{n+m-1}+\theta_{n+m-2}\right\}\left\|x_{n+m-2}-p_{1}\right\|+\exp \left\{\theta_{n+m-1}\right\} \eta_{n+m-2} \\
& +\eta_{n+m-1}+\left\|x_{n}-p_{1}\right\| \leq \cdots \\
\leq & {\left[\exp \left\{\sum_{k=n}^{n+m-1} \theta_{k}\right\}+1\right]\left\|x_{n}-p_{1}\right\|+\exp \left\{\sum_{k=n}^{n+m-1} \theta_{k}\right\} \sum_{k=n}^{n+m-1} \eta_{k}<\varepsilon . }
\end{aligned}
$$

Hence, $\left\{x_{n}\right\}$ is a Cauchy sequence in $E$. By the completeness of $E$, we can assume that $x_{n} \rightarrow x^{*} \in K$. Next we prove that $F(T)$ is a close subset of $K$. Let $\left\{p_{n}\right\}$ is a sequence in $F(T)$ which converges strongly to some $p$, then we have for any $i \in I$

$$
\left\|p-T_{i} p\right\| \leq\left\|p-p_{n}\right\|+\left\|p_{n}-T_{i} p\right\| \leq(1+L)\left\|p-p_{n}\right\| \rightarrow 0 \quad(n \rightarrow \infty) .
$$

Thus, $p \in F(T)$, and $F(T)$ is closed. Since $\lim _{n \rightarrow \infty} d\left(x_{n}, F(T)\right)=0$, then $x^{*} \in F(T)$. Consequently, $\left\{x_{n}\right\}$ defined by (7) converges strongly to a common fixed point of $\left\{T_{1}, T_{2}, \ldots, T_{N}\right\}$ in $K$. This completes the proof of Theorem 3.1.

Theorem 3.2 Let E be a real uniformly convex Banach space satisfying Opial's condition and $K$ be a nonempty closed convex subset of $E$. Let $T_{1}, T_{2}, \ldots, T_{N}: K \rightarrow K$ be $N$ asymptotically nonexpansive mappings with $F(T)=\bigcap_{i=1}^{N} F\left(T_{i}\right) \neq \varnothing$. Let $\left\{u_{n}\right\}$ and $\left\{v_{n}\right\}$ are two bounded sequences in $K$. If $\left\{\alpha_{n}\right\},\left\{\beta_{n}\right\},\left\{\gamma_{n}\right\},\left\{\delta_{n}\right\}$ be four real sequences in $[0,1]$ satisfying the following conditions:

(i) $\alpha_{n}+\gamma_{n} \leq 1$ and $\beta_{n}+\delta_{n} \leq 1$ for all $n \geq 1$;

(ii) $0<\liminf _{n \rightarrow \infty} \alpha_{n} \leq \limsup _{n \rightarrow \infty} \alpha_{n}<1$, limsup $\sin _{n \rightarrow \infty} \beta_{n}<1$;

(iii) $\sum_{n=1}^{\infty} \gamma_{n}<\infty, \sum_{n=1}^{\infty} \delta_{n}<\infty, \sum_{n=1}^{\infty}\left(h_{n}-1\right)<\infty$;

(iv) $\sum_{n=1}^{\infty}\left\|\tilde{x}_{n}-x_{n}\right\|<\infty$.

Then the perturbed composite implicit iterative sequence $\left\{x_{n}\right\}$ defined by (7) converges weakly to a common fixed point of $\left\{T_{1}, T_{2}, \ldots, T_{N}\right\}$ in $K$. 
Proof First, we prove that $\lim _{n \rightarrow \infty}\left\|x_{n}-T_{j} x_{n}\right\|=0$ for all $j \in I$.

For any $p \in F(T)$, it follows from Lemma 2.6 that $\lim _{n \rightarrow \infty}\left\|x_{n}-p\right\|$ exists. Suppose that $\lim _{n \rightarrow \infty}\left\|x_{n}-p\right\|=d$, we have from (7)

$$
\begin{aligned}
\lim _{n \rightarrow \infty}\left\|x_{n}-p\right\|= & \lim _{n \rightarrow \infty} \|\left(1-\alpha_{n}\right)\left[x_{n-1}-p+\gamma_{n}\left(u_{n}-x_{n-1}\right)\right] \\
& +\alpha_{n}\left[T_{i(n)}^{k(n)} y_{n}-p+\gamma_{n}\left(u_{n}-x_{n-1}\right)\right] \|=d .
\end{aligned}
$$

Since $\lim _{n \rightarrow \infty}\left\|x_{n}-p\right\|=d$, then $\left\{x_{n}\right\}$ be a bounded sequence. By virtue of the condition (iii) and the boundedness of sequences $\left\{x_{n}\right\}$ and $\left\{u_{n}\right\}$, we have

$$
\begin{aligned}
& \limsup _{n \rightarrow \infty}\left\|x_{n-1}-p+\gamma_{n}\left(u_{n}-x_{n-1}\right)\right\| \\
& \quad \leq \limsup _{n \rightarrow \infty}\left\|x_{n-1}-p\right\|+\limsup _{n \rightarrow \infty} \gamma_{n}\left\|u_{n}-x_{n-1}\right\|=d .
\end{aligned}
$$

It follows from $\sum_{n=1}^{\infty}\left\|\tilde{x}_{n}-x_{n}\right\|<\infty$ that $\lim _{n \rightarrow \infty}\left\|\tilde{x}_{n}-p\right\|=\lim _{n \rightarrow \infty}\left\|x_{n}-p\right\|=d$. We have

$$
\begin{aligned}
& \limsup _{n \rightarrow \infty}\left\|T_{i(n)}^{k(n)} y_{n}-p+\gamma_{n}\left(u_{n}-x_{n-1}\right)\right\| \\
& \quad \leq \limsup _{n \rightarrow \infty} h_{n}\left\|y_{n}-p\right\|+\limsup _{n \rightarrow \infty} \gamma_{n}\left\|u_{n}-x_{n-1}\right\| \\
& \quad \leq \limsup _{n \rightarrow \infty}\left[\left(1-\beta_{n}-\delta_{n}\right)\left\|x_{n-1}-p\right\|+\beta_{n} h_{n}\left\|\tilde{x}_{n}-p\right\|+\delta_{n}\left\|v_{n}-p\right\|\right]=d .
\end{aligned}
$$

Therefore, by (19), (20), (21), (ii) and Lemma 2.4, we obtain that

$$
\lim _{n \rightarrow \infty}\left\|T_{i(n)}^{k(n)} y_{n}-x_{n-1}\right\|=0
$$

Hence,

$$
\lim _{n \rightarrow \infty}\left\|x_{n}-x_{n-1}\right\| \leq \lim _{n \rightarrow \infty}\left[\alpha_{n}\left\|T_{i(n)}^{k(n)} y_{n}-x_{n-1}\right\|+\gamma_{n}\left\|u_{n}-x_{n-1}\right\|\right]=0
$$

which implies that $\lim _{n \rightarrow \infty}\left\|x_{n}-x_{n+j}\right\|=0$ for all $j \in I$. On the other hand, we also have

$$
\begin{aligned}
\lim _{n \rightarrow \infty}\left\|T_{i(n)}^{k(n)} x_{n}-x_{n}\right\| & \leq \lim _{n \rightarrow \infty}\left[\left\|x_{n}-x_{n-1}\right\|+\left\|x_{n-1}-T_{i(n)}^{k(n)} y_{n}\right\|+\left\|T_{i(n)}^{k(n)} y_{n}-T_{i(n)}^{k(n)} x_{n}\right\|\right] \\
& \leq \lim _{n \rightarrow \infty} h_{n}\left\|y_{n}-x_{n}\right\| \leq \lim _{n \rightarrow \infty}\left\|y_{n}-x_{n-1}\right\|+\lim _{n \rightarrow \infty}\left\|x_{n}-x_{n-1}\right\| \\
& \leq \lim _{n \rightarrow \infty}\left[\beta_{n}\left\|T_{i(n)}^{k(n)} \tilde{x}_{n}-x_{n-1}\right\|+\delta_{n}\left\|v_{n}-x_{n-1}\right\|\right] \\
& \leq \lim _{n \rightarrow \infty}\left[\beta_{n}\left\|T_{i(n)}^{k(n)} \tilde{x}_{n}-T_{i(n)}^{k(n)} x_{n}\right\|+\beta_{n}\left\|T_{i(n)}^{k(n)} x_{n}-x_{n-1}\right\|\right] \\
& \leq \lim _{n \rightarrow \infty}\left[\beta_{n} h_{n}\left\|\tilde{x}_{n}-x_{n}\right\|+\beta_{n}\left\|T_{i(n)}^{k(n)} x_{n}-x_{n}\right\|+\beta_{n}\left\|x_{n-1}-x_{n}\right\|\right] .
\end{aligned}
$$

It follows from (22), (23), conditions (ii) and (iv) that

$$
\lim _{n \rightarrow \infty}\left\|T_{i(n)}^{k(n)} x_{n}-x_{n}\right\|=0
$$


Since for each $n>N, n=(n-N)(\bmod N), n=(k(n)-1) N+i(n)$, hence $n-N=[(k(n)-$ 1) -1$] N+i(n-N)$, i.e. $k(n-N)=k(n)-1$ and $i(n-N)=i(n)$. Therefore, we have

$$
\left\|T_{n}^{k(n)-1} x_{n}-T_{n-N}^{k(n)-1} x_{n-N}\right\|=\left\|T_{n}^{k(n)-1} x_{n}-T_{n}^{k(n)-1} x_{n-N}\right\| \leq L\left\|x_{n}-x_{n-N}\right\|
$$

and

$$
\left\|T_{n-N}^{k(n)-1} x_{n-N}-x_{n-N}\right\|=\left\|T_{n-N}^{k(n-N)} x_{n-N}-x_{n-N}\right\| .
$$

In view of (25) and (26), we have

$$
\begin{aligned}
\left\|x_{n-1}-T_{n} x_{n}\right\| \leq & \left\|x_{n-1}-T_{n}^{k(n)} x_{n}\right\|+\left\|T_{n} x_{n}-T_{n}^{k(n)} x_{n}\right\| \\
\leq & \left\|x_{n}-x_{n-1}\right\|+\left\|x_{n}-T_{n}^{k(n)} x_{n}\right\|+L\left\|x_{n}-T_{n}^{k(n)-1} x_{n}\right\| \\
\leq & \left\|x_{n}-x_{n-1}\right\|+\left\|x_{n}-T_{n}^{k(n)} x_{n}\right\| \\
& \quad+L\left(\left\|T_{n}^{k(n)-1} x_{n}-T_{n-N}^{k(n)-1} x_{n-N}\right\|+\left\|T_{n-N}^{k(n)-1} x_{n-N}-x_{n}\right\|\right) \\
\leq & \left\|x_{n}-x_{n-1}\right\|+\left\|x_{n}-T_{n}^{k(n)} x_{n}\right\| \\
& +\left(L^{2}+L\right)\left\|x_{n}-x_{n-N}\right\|+L\left\|T_{n-N}^{k(n-N)} x_{n-N}-x_{n-N}\right\| .
\end{aligned}
$$

From (24) and (27), it is obviously that $\lim _{n \rightarrow \infty}\left\|x_{n-1}-T_{n} x_{n}\right\|=0$, which implies that

$$
\lim _{n \rightarrow \infty}\left\|x_{n}-T_{n} x_{n}\right\| \leq \lim _{n \rightarrow \infty}\left(\left\|x_{n-1}-T_{n} x_{n}\right\|+\left\|x_{n}-x_{n-1}\right\|\right)=0
$$

Consequently, we obtain that for all $i \in I$

$$
\begin{aligned}
\left\|x_{n}-T_{n+i} x_{n}\right\| & \leq\left\|x_{n}-x_{n+i}\right\|+\left\|x_{n+i}-T_{n+i} x_{n+i}\right\|+\left\|T_{n+i} x_{n+i}-T_{n+i} x_{n}\right\| \\
& \leq(1+L)\left\|x_{n}-x_{n+i}\right\|+\left\|x_{n+i}-T_{n+i} x_{n+i}\right\| \rightarrow 0 \quad(n \rightarrow \infty) .
\end{aligned}
$$

By virtue of (28), we have $\lim _{n \rightarrow \infty}\left\|x_{n}-T_{i} x_{n}\right\|=0$ for all $i \in I$.

Since $E$ is uniformly convex, every bounded subset of $E$ is weakly compact. Again since $\left\{x_{n}\right\}$ is a bounded subset in $K$, there exists a subsequence $\left\{x_{n_{k}}\right\}$ of $\left\{x_{n}\right\}$ such that $\left\{x_{n_{k}}\right\}$ converges weakly to $q$ in $K$, and $\lim _{n_{k} \rightarrow \infty}\left\|x_{n_{k}}-T_{i} x_{n_{k}}\right\|=0$ for all $i \in I$. By Lemma 2.2, we have that $\left(I-T_{i}\right) q=0$. Hence, $q \in F\left(T_{i}\right)$ for all $i \in I$. Therefore, $q \in F(T)$.

Next, we prove that $\left\{x_{n}\right\}$ converges weakly to $q$. Suppose that contrary, then there exists a subsequence $\left\{x_{n_{j}}\right\}$ of $\left\{x_{n}\right\}$ such that $\left\{x_{n_{j}}\right\}$ converges weakly to $q_{1} \in K$ and $q \neq q_{1}$. Using the same method, we can prove that $q_{1} \in F(T)$ and $\operatorname{limit}_{n \rightarrow \infty}\left\|x_{n}-q_{1}\right\|$ exists. Without loss generality, we assume that $\lim _{n \rightarrow \infty}\left\|x_{n}-q\right\|=d_{1}, \lim _{n \rightarrow \infty}\left\|x_{n}-q_{1}\right\|=d_{2}$, where $d_{1}, d_{2}$ are two nonnegative constants. By virtue of the Opial's condition of $E$, we have

$$
\begin{aligned}
d_{1} & =\limsup _{n_{k} \rightarrow \infty}\left\|x_{n_{k}}-q\right\|<\limsup _{n_{k} \rightarrow \infty}\left\|x_{n_{k}}-q_{1}\right\|=\limsup _{n \rightarrow \infty}\left\|x_{n}-q_{1}\right\| \\
& =\limsup _{n_{j} \rightarrow \infty}\left\|x_{n_{j}}-q_{1}\right\|<\limsup _{n_{j} \rightarrow \infty}\left\|x_{n_{j}}-q\right\|=d_{1} .
\end{aligned}
$$

This is contradictory. Hence, $q=q_{1}$, which implies that $\left\{x_{n}\right\}$ converges weakly to $q$. The proof of Theorem 3.2 is completed. 
Theorem 3.3 Let E be a real uniformly convex Banach space and $K$ be a nonempty, closed and convex subset of $E$. Let $T_{1}, T_{2}, \ldots, T_{N}: K \rightarrow K$ be $N$ asymptotically nonexpansive mappings with $F(T)=\bigcap_{i=1}^{n} F\left(T_{i}\right) \neq \varnothing$ and at least there exists $T_{i}(i \in I)$, it is semicompact. Let $\left\{u_{n}\right\}$ and $\left\{v_{n}\right\}$ are two bounded sequences in $K$. If $\left\{\alpha_{n}\right\},\left\{\beta_{n}\right\},\left\{\gamma_{n}\right\},\left\{\delta_{n}\right\}$ be four real sequences in $[0,1]$ satisfying the following conditions:

(i) $\alpha_{n}+\gamma_{n} \leq 1$ and $\beta_{n}+\delta_{n} \leq 1$ for all $n \geq 1$;

(ii) $0<\liminf _{n \rightarrow \infty} \alpha_{n} \leq \limsup \sup _{n \rightarrow \infty} \alpha_{n}<1, \limsup _{n \rightarrow \infty} \beta_{n}<1$;

(iii) $\sum_{n=1}^{\infty} \gamma_{n}<\infty, \sum_{n=1}^{\infty} \delta_{n}<\infty, \sum_{n=1}^{\infty}\left(h_{n}-1\right)<\infty$;

(iv) $\sum_{n=1}^{\infty}\left\|\tilde{x}_{n}-x_{n}\right\|<\infty$.

Then the perturbed composite implicit iterative sequence $\left\{x_{n}\right\}$ defined by (7) converges strongly to a common fixed point of $\left\{T_{1}, T_{2}, \ldots, T_{N}\right\}$ in $K$.

Proof Without loss of generality, we assume that $T_{1}$ is semicompact. By Theorem 3.2, we have $\lim _{n \rightarrow \infty}\left\|x_{n}-T_{1} x_{n}\right\|=0$. Hence, there exists a subsequence $\left\{x_{n_{j}}\right\}$ of $\left\{x_{n}\right\}$ such that $\left\{x_{n_{j}}\right\} \rightarrow x^{*}$ as $j \rightarrow \infty$. Therefore, we have for all $i \in I$

$$
\left\|T_{i} x^{*}-x^{*}\right\| \leq\left\|T_{i} x^{*}-T_{i} x_{n_{j}}\right\|+\left\|T_{i} x_{n_{j}}-x_{n_{j}}\right\|+\left\|x_{n_{j}}-x^{*}\right\| .
$$

It follows from (29) that $\left\|T_{i} x^{*}-x^{*}\right\|=0$ for all $i \in I$. This implies that $x^{*} \in F(T)$. Therefore, $x^{*}$ be a common fixed point of $\left\{T_{i}, i \in I\right\}$. By virtue of Lemma 2.6, $\lim _{n \rightarrow \infty}\left\|x_{n}-x^{*}\right\|$ exists. It follows from $x_{n_{j}} \rightarrow x^{*} \in E$ that $\lim _{n \rightarrow \infty}\left\|x_{n}-x^{*}\right\|=0$. Hence, the perturbed composites implicit iterative sequence $\left\{x_{n}\right\}$ generated by (7) strongly converges to a common fixed point of $\left\{T_{i}, i \in I\right\}$. This completes the proof of Theorem 3.3.

Corollary 3.4 Let $E$ be a real Banach space and $K$ be a nonempty closed convex subset of $E$. Let $T_{1}, T_{2}, \ldots, T_{N}: K \rightarrow K$ be $N$ asymptotically nonexpansive mappings with $F(T)=$ $\bigcap_{i=1}^{N} F\left(T_{i}\right) \neq \varnothing$ and let $\left\{u_{n}\right\}$ is a bounded sequence in $K$. If $\left\{\alpha_{n}\right\},\left\{\gamma_{n}\right\}$ be two real sequences in $[0,1]$ satisfying the following conditions:

(i) $\alpha_{n}+\gamma_{n} \leq 1$ for all $n \geq 1$;

(ii) $\lim \sup _{n \rightarrow \infty} \alpha_{n}<1$;

(iii) $\sum_{n=1}^{\infty} \gamma_{n}<\infty, \sum_{n=1}^{\infty}\left(h_{n}-1\right)<\infty$;

(iv) $\sum_{n=1}^{\infty}\left\|\tilde{x}_{n}-x_{n}\right\|<\infty$.

Then the perturbed implicit iterative sequence $\left\{x_{n}\right\}$ defined by (9) converges strongly to a common fixed point of $\left\{T_{1}, T_{2}, \ldots, T_{N}\right\}$ if and only if $\liminf _{n \rightarrow \infty} d\left(x_{n}, F(T)\right)=0$.

Proof It is enough to take $\beta_{n}=1, \delta_{n}=0$ for all $n \in \mathbb{N}$ in Theorem 3.1.

Corollary 3.5 Let E be a real uniformly convex Banach space satisfying Opial's condition and $K$ be a nonempty closed convex subset of $E$. Let $T_{1}, T_{2}, \ldots, T_{N}: K \rightarrow K$ be $N$ asymptotically nonexpansive mappings with $F(T)=\bigcap_{i=1}^{N} F\left(T_{i}\right) \neq \varnothing$ and let $\left\{u_{n}\right\}$ is a bounded sequence in $K$. If $\left\{\alpha_{n}\right\},\left\{\gamma_{n}\right\}$ be two real sequences in $[0,1]$ satisfying the following conditions:

(i) $\alpha_{n}+\gamma_{n} \leq 1$ for all $n \geq 1$;

(ii) $0<\liminf _{n \rightarrow \infty} \alpha_{n} \leq \limsup _{n \rightarrow \infty} \alpha_{n}<1$;

(iii) $\sum_{n=1}^{\infty} \gamma_{n}<\infty, \sum_{n=1}^{\infty}\left(h_{n}-1\right)<\infty$.

Then the Mann type iterative sequence $\left\{x_{n}\right\}$ defined by (8) converges weakly to a common fixed point of $\left\{T_{1}, T_{2}, \ldots, T_{N}\right\}$ in $K$. 
Proof It is sufficient to take $\beta_{n}=\delta_{n}=0$ for all $n \in \mathbb{N}$ in Theorem 3.2.

Corollary 3.6 Let E be a real uniformly convex Banach space and $K$ be a nonempty closed convex subset of $E$. Let $T_{1}, T_{2}, \ldots, T_{N}: K \rightarrow K$ be $N$ asymptotically nonexpansive mappings with $F(T)=\bigcap_{i=1}^{n} F\left(T_{i}\right) \neq \varnothing$ and at least there exists $T_{i}(i \in I)$, it is semicompact. Let $\left\{u_{n}\right\}$ is a bounded sequence in $K$. If $\left\{\alpha_{n}\right\},\left\{\gamma_{n}\right\}$ be two real sequences in $[0,1]$ satisfying the following conditions:

(i) $\alpha_{n}+\gamma_{n} \leq 1$ for all $n \geq 1$;

(ii) $0<\liminf _{n \rightarrow \infty} \alpha_{n} \leq \limsup _{n \rightarrow \infty} \alpha_{n}<1$;

(iii) $\sum_{n=1}^{\infty} \gamma_{n}<\infty, \sum_{n=1}^{\infty}\left(h_{n}-1\right)<\infty$.

Then the Mann type iterative sequence $\left\{x_{n}\right\}$ defined by (8) converges strongly to a common fixed point of $\left\{T_{1}, T_{2}, \ldots, T_{N}\right\}$ in $K$.

Proof It is enough to take $\beta_{n}=\delta_{n}=0$ for all $n \in \mathbb{N}$ in Theorem 3.3.

\section{Competing interests}

The author did not provide this information.

\section{Acknowledgements}

The authors are grateful to the anonymous referee for valuable suggestions which helped to improve this manuscript.

Received: 4 July 2012 Accepted: 26 March 2013 Published: 12 April 2013

References

1. Xu, HK, Ori, RG: An implicit iteration process for nonexpansive mappings. Numer. Funct. Anal. Optim. 22, 767-773 (2001)

2. Sun, ZH: Strong convergence of an implicit iteration process for a finite family of asymptotically quasi-nonexpansive mappings. J. Math. Anal. Appl. 286, 351-358 (2003)

3. Chang, SS, Tan, KK, Lee, HWJ, Chan, CK: On the convergence of implicit iteration process with error for a finit family of asymptotically nonexpansive mappings. J. Math. Anal. Appl. 313, 273-283 (2006)

4. Gu, F: The new composite implicit iterative process with errors for common fixed points of a finite family of strictly pseudocontractive mappings. J. Math. Anal. Appl. 329, 766-776 (2007)

5. Thakur, BS: Weak and strong convergence of composite implicit iteration process. Appl. Math. Comput. 190, 965-973 (2007)

6. Rafiq, A: Implicit fixed point iterations. Rostock. Math. Kolloqu. 62, 21-39 (2007)

7. Ciric, L, Rafiq, A, Cakic, N, Ume, JS: Implicit Mann fixed point iterations for pseudo-contractive mappings. Appl. Math. Lett. 22, 581-584 (2009)

8. Osilike, MO: Implicit iteration process for commom fixed points of a finite family of strictly pseudocontractive maps. J. Math. Anal. Appl. 294, 73-81 (2004)

9. Marino, G, Xu, HK: Weak and strong convergence theorems for strict pseudo-contraction in Hilbert spaces. J. Math. Anal. Appl. 329, 336-346 (2007)

10. Chen, RD, Song, YS, Zhou, HY: Convergence theorems for implicit iteration process for a finite family of continuous pseudocontractive mappings. J. Math. Anal. Appl. 314, 701-709 (2006)

11. Cho, YJ, Zhou, HY, Gou, G: Weak and strong convergence theorems for three-step iterations with errors for asymptotically nonexpansive mappings. Comput. Math. Appl. 47, 707-717 (2004)

12. Cianciaruso, F, Marino, G, Wang, XW: Weak and strong convergence of the Ishikawa iterative process for a finite family of asymptotically nonexpansive mappings. Appl. Math. Comput. 216, 3558-3567 (2010)

13. Yildirim, I, Khan, SH: A new one-step implicit iterative process for common fixed points of two asymptotically nonexpansive mappings in Banach spaces. Expo. Math. 29(2), 240-251 (2011)

14. Khan, SH, Yildirim, I, Ozdemir, M: Convergence of a generalized iteration process for two finite families of Lipschitzian pseudocontractive mappings. Math. Comput. Model. 53, 707-715 (2011)

15. Khan, SH, Hussain, N: Convergence theorems for nonself asymptotically nonexpansive mappings. Comput. Math Appl. 55, 2544-2553 (2008)

16. Opial, Z: Weak convergence of successive approximations for nonexpansive mappings. Bull. Am. Math. Soc. 73, 591-597 (1967)

17. Chang, SS, Chao, YJ, Zhao, HY: Demi-closed principle and weak convergence problems for asymptotically nonexpansive mappings. J. Korean Math. Soc. 38, 1245-1260 (2001)

18. Hicks, TL, Kubicek, JD: On the Mann iteration process in a Hilbert space. J. Math. Anal. Appl. 59, $498-504$ (1977)

19. Schu, J: Weak and strong convergence of fixed points of asymptotically nonexpansive mappings. Bull. Aust. Math. Soc. 43, 153-159 (1991)

20. Tan, KK, Xu, HK: Approximating fixed points of nonexpansive mappings by the Ishikawa iterative process. J. Math. Anal. Appl. 178, 301-308 (1993) 
doi:10.1186/1687-1812-2013-97

Cite this article as: Wang: Convergence of perturbed composite implicit iteration process for a finite family of asymptotically nonexpansive mappings. Fixed Point Theory and Applications 2013 2013:97.

Submit your manuscript to a SpringerOpen ${ }^{\circ}$ journal and benefit from:

- Convenient online submission

- Rigorous peer review

- Immediate publication on acceptance

- Open access: articles freely available online

- High visibility within the field

- Retaining the copyright to your article

Submit your next manuscript at $\gg$ springeropen.com 